\title{
Photosensitive Rice (Oryza sativa L.) Varieties under Delayed Planting as an Option to Minimize Rice Yield Loss in Flood Affected T. Aman Season
}

\author{
A Biswas ${ }^{1 *}$, M M E Ahmed ${ }^{2}$, T Halder ${ }^{1}$, S Akter $^{1}$, R Yasmeen ${ }^{1}$ and M S Rahman ${ }^{1}$
}

\begin{abstract}
Photosensitive rice varieties have higher advantages in delayed planting. The present study was undertaken to figure out the degrees of delayed planting and evaluate the performance of six modern Aman rice varieties (BR11, BR22, BR23, BRRI dhan46, BRRI dhan54) against three sets of delayed planting. Each rice variety showed considerable variations for plant height, days to panicle initiation, flowering and maturity. BR22, BR23, and BRRI dhan54 showed a drastic reduction in days to panicle initiation and varied from 65 to 58 days, 69 to 60 days, and 62 to 55 days respectively, while it varied from 76 to 80 days for the control variety BR11. Similarly, days to flowering of BR22 and BRRI dhan54 showed a gradual decrease following different planting time and varied from 92 to 86 days, and 83 to 77 days respectively, while it varied from 109 to 107 days for the control variety BR11. For the above traits, BRRI dhan44 and BRRI dhan46 showed a moderate reduction depending on the three sets of planting time. Grain yield of BR22, BR23 reduced at the third set with a value ranging from 5.8 to $5.0 \mathrm{t} / \mathrm{ha}, 6.1$ to $5.1 \mathrm{t} /$ ha respectively, while BRRI dhan54 showed consistency in grain yield with a range from 5.3 to $5.2 \mathrm{t} / \mathrm{ha}$. In contrast, grain yield of remaining rice varieties ranged between 5.7 to $4.5 \mathrm{t}$ / ha for BRRI dhan46, 6.2 to $3.9 \mathrm{t}$ / ha for BRRI dhan46 while severe reduction for the control variety BR11 with a range from 4.4 to $2.0 \mathrm{t} /$ ha was observed. In conclusion, BRRI dhan54 was found more suitable rice variety in delayed planting compared with other photosensitive rice varieties. In future, BRRI dhan 54 could be used as benchmark rice variety in a special rice breeding programme designed for delayed planting.
\end{abstract}

Key words: Delayed planting, photosensitive rice, physiological growth, grain yield

\section{INTRODUCTION}

Rice is grown worldwide with broad variation in photoperiod which affects the planting time and the growth in respective areas (Izawa et al. 2007; Song et al. 2007). In Bangladesh, rice cultivation is practiced throughout the year which has been mainly divided as Aus, Aman, and Boro (Parsons et al. 1999; Shelly et al. 2016). Aman rice is grown in the wet season when most of the rainfall come about. Sometimes heavy rainfall and sudden increase in water flow from the upstream of the main rivers causes the late flooding. In this situation, Aman plantation is seriously impaired due to the inundation of floodwater in the main rice field as well as damage to the seedbed.
Furthermore, Bangladesh is the most vulnerable country for climate change. In recent times, the country is experiencing more extreme climate conditions such as an irregular pattern of rainfall in the monsoon, drought and high temperature during summer.

For a long time, farmers of Bangladesh are practicing the cultivation of photosensitive rice varieties after the recession of floodwater. These photosensitive Aman rice varieties are transplanted in the late season from August to September. Their sensitivity to flowering occurs in October or November depending on the planting time. These varieties mostly include Bangladeshi local rice varieties. Although, Bangladesh Rice Research Institute (BRRI) has developed some high yielding photosensitive rice varieties such as BR22,

1Plant Physiology Division, BRRI, and 'Plant Breeding Division, BRRI, Gazipur, Bangladesh. *Corresponding author's E-mail: avijitbrri@gmail.com 
BR23, and BRRI dhan46 which have also become popular among the rice growers. However, further study is needed to characterize the features of seasonal variation concerning the transplanting time, growth stages and yield of modern rice varieties. It requires a certain temperature for the phonological events of rice plants like panicle initiation, flowering, panicle exertion and maturity, and these are much governed by the planting date during T. Aman season. The fluctuation from optimum planting time might be responsible for incomplete and irregular panicle exertion, increased spikelet sterility (Yoshida 1981). In general, T. Aman rice is planted from $15^{\text {th }}$ July to $15^{\text {th }}$ August. Sometimes transplanting is delayed due to the physical and socioeconomic factors. Moreover, flash floods affect $24 \%$ of rainfed lowland Aman rice areas, mainly at the seedling stage. The unpredictable rainfall often delays Aman transplanting in Bangladesh (Iftekharuddaula et al. 2015).

Aman season is a rain-fed season, which means that the onset of the season entirely depends on the starting of the monsoon. In recent times, the climatic change affects the season tremendously; sometimes the season is shifted mainly due to no rainfall at the starting of the season or heavy rainfall at mid or late of the season prompted to flood causing serious damage. Considering the above facts, if the season is shifted towards late then there might be a risk of cold injury during reproductive development of weak or moderately photosensitive varieties. In such conditions, strong photo-sensitive varieties are suitable for cultivation and numerous studies have been performed using both the local and modern Aman rice varieties of Bangladesh (Ali et al. 1993; Halder et al. 1995; Roy et al. 2003). In this context, BRRI has so far developed several strong photosensitive rice varieties (BR22, BR23, BRRI dhan44, BRRI dhan46 and BRRI dhan54), among these BR22 and BR23 are suitable for late or delayed planting. However, information regarding the effect of low temperature in case of delayed plantation in the T. Aman season is not adequate. Therefore, the present study was under taken to figure out the degrees of delayed plantation and evaluate the performance of six modern Aman rice varieties (BR11, BR22, BR23, BRRI dhan46, BRRI dhan54) against three sets of delayed planting in T. Aman season.

\section{MATERIALS AND METHODS}

\section{Plant materials}

BRRI has so far developed five photosensitive rice varieties namely BR22, BR23, BRRI dhan44, BRRI dhan46 and BRRI dhan54 along with BR11 as control were selected to execute the experiment.

\section{Growing rice plants in the field}

The experiment was carried out in the research field of the Plant Physiology Division located at BRRI Gazipur, Bangladesh during T. Aman 2017. Three different planting time including $30^{\text {th }}$ August, $6^{\text {th }}$ September and $13^{\text {th }}$ September were considered as three sets of delayed planting and designated as $1^{\text {st }}$ set, $2^{\text {nd }}$ set, and $3^{\text {rd }}$ set respectively. Seedlings were raised in the ideal seed beds and uprooted for transplanting at five leaves stage. By following planting dates, seedlings were transplanted in well puddle paddy soils. The experiment was laid out in a split plot design with three replications. Three sets of transplanting dates were placed in the main plots and varieties in the sub-plots. The unit plot size was designed $2.5 \mathrm{~m} \times 2.0 \mathrm{~m}$ followed by $20 \mathrm{~cm} \times 20 \mathrm{~cm}$ spacing. Fertilizer doses were applied as urea, triple super phosphate, muriate of potash, and gypsum @ 80-50-50-10 kg per hectare for N, $\mathrm{P}_{2} \mathrm{O}_{5}, \mathrm{~K}_{2} \mathrm{O}$ and $\mathrm{S}$ respectively. Full doses of triple super phosphate, muriate of potash, and gypsum were incorporated at the time of final land preparation while urea was applied in three equal splits at 15,30 and 45 days after 
transplanting.

During the growing period, intercultural opera tions were carried out as necessary.

\section{Evaluation of agronomic traits}

Data on plant height, days to panicle initiation, days to flowering, days to maturity were recorded in the suitable growth stages of rice varieties. For yield estimation, the whole plot was harvested and grain yield of each plot was recorded accordingly.

\section{Data analysis}

Data analyses were performed using Statistical Tool for Agricultural Research (STAR), version 2.0.1, developed by International Rice Research Institute (STAR, 2013).

\section{RESULTS}

\section{Variation in major agronomic traits}

The plant height of all rice varieties showed significant changes based on three sets of delayed planting except for BRRI dhan54 (Tables 1 and 2). Among the varieties, it was reduced drastically for BR22, BR23, BRRI dhan44, and BRRI dhan46 with a value between 122.3 to $95.7 \mathrm{~cm}, 132.2$ to $106.2 \mathrm{~cm}$, 132.0 to $112.8 \mathrm{~cm}, 136.0$ to $106.9 \mathrm{~cm}$ respectively. In case of BRRI dhan54, it changed from 113.1 to $104.3 \mathrm{~cm}$ and varied only in the third set of treatment. But, the plant height of control variety BR11 was not changed significantly and varied between 109.1 to $105.8 \mathrm{~cm}$. For days to panicle initiation, significant variation was observed among three sets of delayed plantations (Tables 1 and 2). In case of BR22, BR23, and BRRI dhan54, it reduced drastically following three different planting times and varied from 65 to 58 days, 69 to 60 days, and 62 to 55 days respectively. Conversely, it was longer in the third set for BRRI dhan44 and BRRI dhan46 and varied from 72 to 63 days, and 68 to 63 days respectively. Among three sets of delayed planting, it was observed significantly longer for the control variety BR11 at the third set of planting time and varied from 80 to 76 days. Like panicle initiation, significant variation was observed for days to flowering among three sets of delayed plantations (Tables 1 and 2). Flowering time of BR22 and BRRI dhan54 showed a gradual decrease following different planting times and varied from 92 to 86 days, and 83 to 77 days respectively. But BR23 and BRRI dhan44 showed opposite fashion for days to flowering with longer time for first set and third set respectively, and it varied from 98 to 93 days for BR23 and 92 to 101 days for BRRI dhan44. However, BRRI dhan 46 and the control variety BR11 had a similar tendency of flowering time with a significant difference only in the second set and it varied from 93 to 90 days for BRRI dhan46 and 109 to 107 days for BR11. Different patterns of days to maturity were found among evaluated rice varieties based on three sets of planting time (Tables 1 and 2). For BR22, it was reduced only in the third set from 121 to 116 days. BR23 and BRRI dhan44 showed a gradual increase in maturity time and it was significantly higher at the third set, with a range from 125 to 120 days, and 133 to 118 days respectively. For BRRI dhan46, it was shorter in the second set and longer in the third set with a value from 123 to 117 days. In comparison, BRRI dhan54 showed a gradual decrease in maturity over delayed planting with a range from 107 to 100 days. Days to maturity of BR11 decreased at the second set and had a similarity between the first set and third set with a range from 140 to 138 days. The grain yield of evaluated rice varieties showed significant variation based on the three planting times (Fig. 1). BR22, BR23, and BRRI dhan46 had a significant reduction in yield at the third set with a value from 5.8 to $5.0 \mathrm{t} \mathrm{ha}^{-1}, 6.1$ to $5.1 \mathrm{t} \mathrm{ha}^{-1}$, and 5.7 to $4.5 \mathrm{t} \mathrm{ha}^{-1}$, respectively. But BRRI dhan44 showed a gradual decrease in grain yield with the value ranging from 6.2 to $3.9 \mathrm{t} \mathrm{ha}^{-1}$. In comparison, BRRI dhan54 showed consistency in grain 
Table 1. Analysis of variance for the tested traits against three sets of planting dates.

\begin{tabular}{lcccccccc}
\hline \multirow{2}{*}{ Trait } & \multicolumn{2}{c}{ Sum of squares } & \multicolumn{2}{c}{ Mean square } & \multicolumn{2}{c}{ F value } & \multicolumn{2}{c}{$P$ value } \\
\cline { 2 - 9 } & Genotype & Sets & Genotype & Sets & Genotype & Sets & Genotype & Sets \\
\hline df & 5 & 2 & 5 & 2 & 5 & 2 & 5 & 2 \\
Plant height (cm) & 2271.72 & 3088.11 & 454.34 & 1544.05 & 67.95 & 230.93 & 0.0000 & 0.0000 \\
Days to Panicle & 2034.98 & 122.25 & 406.99 & 61.12 & 362.39 & 54.43 & 0.0000 & 0.0000 \\
initiation & 3926.00 & 73.00 & 785.20 & 36.50 & 743.87 & 34.58 & 0.0000 & 0.0000 \\
Days to Flowering & 6065.64 & 64.92 & 1213.12 & 32.46 & 2010.20 & 53.79 & 0.0000 & 0.0000 \\
Days to maturity & 29.13 & 15.93 & 5.82 & 7.96 & 37.76 & 51.62 & 0.0000 & 0.0000 \\
Yield (t/ha) & & & & & & & &
\end{tabular}

df: degree of freedom

Table 2. Agronomic traits of tested rice varieties based on three sets of delayed planting (different dates of sowing and transplanting).

\begin{tabular}{|c|c|c|c|c|c|c|c|}
\hline \multirow{2}{*}{ Traits } & \multirow{2}{*}{ Set } & \multicolumn{6}{|c|}{ Rice variety } \\
\hline & & BR22 & BR23 & BRRI dhan44 & BRRI dhan46 & BRRI dhan54 & BR11 \\
\hline \multirow{3}{*}{$\begin{array}{l}\text { Plant height } \\
(\mathrm{cm})\end{array}$} & 1 & $122.3 \pm 4.5 a$ & $132.2 \pm 2.5 \mathrm{a}$ & $132.0 \pm 3.0 \mathrm{a}$ & $136.0 \pm 1.6 \mathrm{a}$ & $111.1 \pm 0.9 \mathrm{a}$ & $109.1 \pm 2.8 \mathrm{a}$ \\
\hline & 2 & $105.5 \pm 0 . b$ & $119.7 \pm 1.5 b$ & $120.7 \pm 3.7 b$ & $123.0 \pm 2.6 \mathrm{~b}$ & $113.1 \pm 1.0 \mathrm{a}$ & $107.3 \pm 3.0 \mathrm{a}$ \\
\hline & 3 & $95.7 \pm 5.6 c$ & $106.2 \pm 1.3 \mathrm{c}$ & $112.8 \pm 4.5 c$ & $106.9 \pm 4.2 \mathrm{c}$ & $104.3 \pm 4.6 b$ & $105.8 \pm 2.2 \mathrm{a}$ \\
\hline Days to & 1 & $65.0 \pm 1.0 \mathrm{a}$ & $69.0 \pm 1.0 \mathrm{a}$ & $67.0 \pm 1.0 \mathrm{~b}$ & $67.7 \pm 1.5 \mathrm{a}$ & $62.0 \pm 1.0 \mathrm{a}$ & $76.0 \pm 1.0 \mathrm{~b}$ \\
\hline \multirow{2}{*}{$\begin{array}{l}\text { Panicle } \\
\text { initiation } \\
\text { (day) }\end{array}$} & 2 & $61.0 \pm 1.0 \mathrm{~b}$ & $64.0 \pm 1.0 \mathrm{~b}$ & $63.0 \pm 1.0 \mathrm{c}$ & $63.0 \pm 1.0 \mathrm{~b}$ & $57.0 \pm 1.0 \mathrm{~b}$ & $77.0 \pm 1.0 \mathrm{~b}$ \\
\hline & 3 & $58.0 \pm 1.0 \mathrm{c}$ & $60.0 \pm 1.0 \mathrm{c}$ & $72.0 \pm 1.0 \mathrm{a}$ & $67.0 \pm 1.0 \mathrm{a}$ & $55.0 \pm 1.0 \mathrm{c}$ & $80.0 \pm 1.0 \mathrm{a}$ \\
\hline Days to & 1 & $92.0 \pm 1.0 \mathrm{a}$ & $98.0 \pm 1.0 \mathrm{a}$ & $92.0 \pm 1.0 \mathrm{~b}$ & $92.0 \pm 1.0 \mathrm{a}$ & $83.0 \pm 1.0 \mathrm{a}$ & $109.0 \pm 1.0 \mathrm{a}$ \\
\hline \multirow{2}{*}{$\begin{array}{l}\text { Flowering } \\
\text { (day) }\end{array}$} & 2 & $89.0 \pm 1.0 \mathrm{~b}$ & $93.0 \pm 1.0 \mathrm{~b}$ & $91.0 \pm 1.0 \mathrm{~b}$ & $90.0 \pm 1.0 \mathrm{~b}$ & $79.0 \pm 1.0 \mathrm{~b}$ & $107.0 \pm 1.0 \mathrm{~b}$ \\
\hline & 3 & $86.0 \pm 1.0 \mathrm{c}$ & $93.0 \pm 1.0 \mathrm{~b}$ & $101.0 \pm 1.0 \mathrm{a}$ & $93.0 \pm 1.0 \mathrm{a}$ & $77.0 \pm 1.0 \mathrm{c}$ & $109.0 \pm 1.0 \mathrm{a}$ \\
\hline \multirow{3}{*}{$\begin{array}{l}\text { Days to } \\
\text { maturity } \\
\text { (day) }\end{array}$} & 1 & $121.0 \pm 0.0 \mathrm{a}$ & $120.0 \pm 0.0 \mathrm{c}$ & $118.3 \pm 0.5 c$ & $121.3 \pm 0.5 b$ & $107.0 \pm 0.0 \mathrm{a}$ & $140.0 \pm 0.0 \mathrm{a}$ \\
\hline & 2 & $121.0 \pm 1.0 \mathrm{a}$ & $122.0 \pm 0.0 \mathrm{~b}$ & $121.0 \pm 1.0 \mathrm{~b}$ & $117.3 \pm 0.5 c$ & $102.0 \pm 1.0 \mathrm{~b}$ & $138.0 \pm 1.0 \mathrm{~b}$ \\
\hline & 3 & $116.0 \pm 1 . b$ & $125.0 \pm 1.0 \mathrm{a}$ & $133.3 \pm 0.5 \mathrm{a}$ & $123.0 \pm 1.0 \mathrm{a}$ & $100.0 \pm 1.0 \mathrm{c}$ & $140.0 \pm 1.0 \mathrm{a}$ \\
\hline
\end{tabular}

Note: Data represent mean \pm s.d. of each rice variety in each set of treatment. The mean value of each variety among multiple sets was compared by Tukey's Honest Significant test.

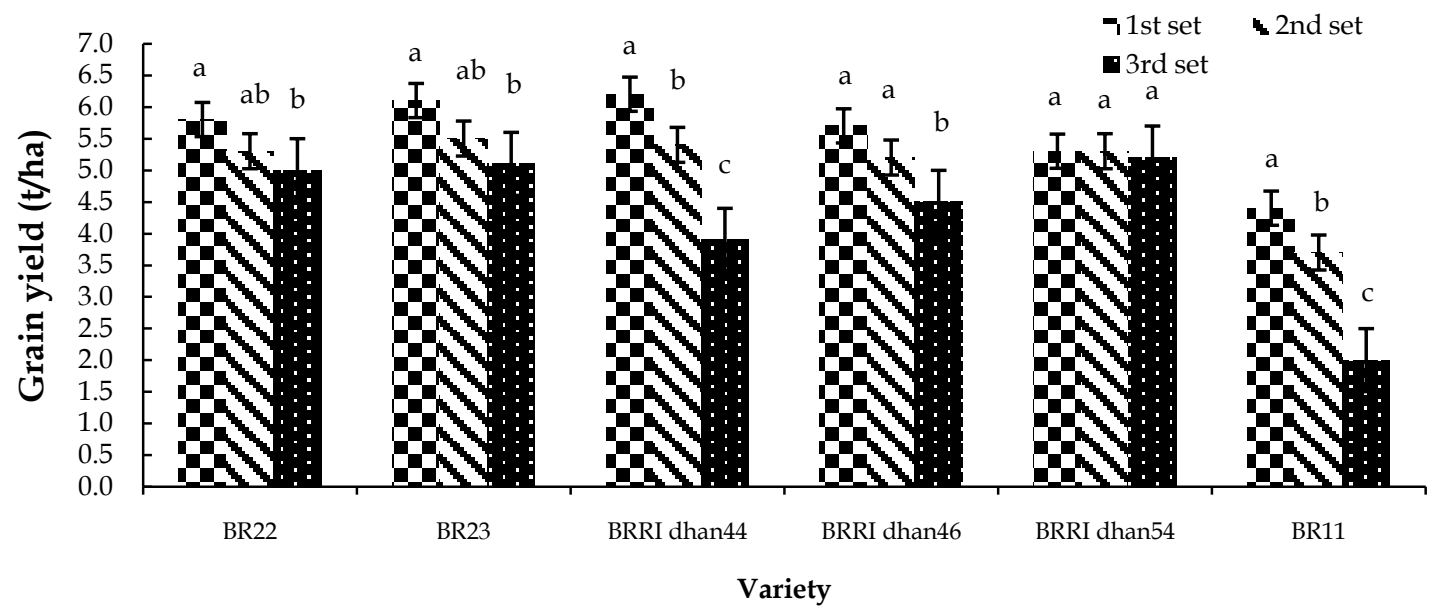

Fig. 1. The yield of five photosensitive rice varieties and the control rice variety BR11 in three sets of delayed planting during the Aman season.

Note: The bars over the column indicate standard deviation for each set and the mean value of each variety among multiple sets was compared by Tukey's Honest Significant test at 0.05 level. 
yield over three sets of different planting time with a range between 5.3 to $5.2 \mathrm{t} \mathrm{ha}^{-1}$. Like BRRI dhan44, the control variety BR11 had a gradual decrease in grain yield depending on planting time with the value ranging from 4.4 to $2.0 \mathrm{t} \mathrm{ha}^{-1}$.

\section{Relationship between sowing date and grain yield}

Among the tested varieties, BR11 produced low yield even in $1^{\text {st }}$ set of sowing. The Rate of yield decrease(-0.174) was maximum in the case of BR11 which indicated that it is not suitable for delayed planting (Fig. 2). On the other hand, BRRI dhan 44 and BRRI dhan 46 produced moderate yield (more or less $5.0 \mathrm{t}$ ha$\left.{ }^{1}\right)$ till $2^{\text {nd }}$ set of sowing. Rate of yield decrease of BRRI dhan44 and BRRI dhan46 were -1.66 and -0.087 respectively. BR23, BR22 and BRRI dhan54 produced moderate yield for all sets of delayed plantation and rate of yield decrease were $-0.069,-0.058,-0.008$ respectively. Among the varieties rate of yield decrease was minimum for in case of BRRI dhan 54 .

\section{DISCUSSIONS}

Significant variation was observed in all the traits (plant height, panicle initiation, days to flowering, days to maturity, and grain yield) depending on three sets of delayed planting in the T. Aman season (Tables 1 and 2). However, variation among photosensitive varieties enabled us to discuss the underlying causes and impacts of environmental factors. Time of transplanting directly influences the growth and yield contributing characters of rice (Islam et al. 1999). Sometimes transplanting in optimum time is not possible due to untimely rainfall or delayed recession of floodwater.

At first, drastic reduction of plant height in all photosensitive rice varieties indicated that vegetative growth is dependent on the existing photoperiod. In contrast, the plant height of control variety BR11 was not changed based on three sets of planting dates. In this study, we observed significant changes in days to panicle initiation among the tested rice varieties. BR22, BR23, and BRRI dhan54 had a dramatic reduction in days to panicle initiation compared to BR11. These results supported that these varieties are strongly photosensitive while BR11 is a weakly photosensitive rice variety. Moreover, a moderate reduction of BRRI dhan 44 and BRRI dhan46 indicated moderate photosensitivity in those varieties. Among strongly photosensitive varieties, a gradual decrease of days to flowering was observed mostly in BR22 and BRRI dhan54 except for BR23. Although they had a similar pattern of panicle initiation based on three sets of planting time. Probably, this has been influenced by environmental factors such as low temperature (Fig. 3). Generally, spikelet sterility of rice is affected by low temperatures during panicle development and these changes happen according to its physiological status during sensitive stages (Shimono et al. 2007).

On the other hand, flowering time is affected by both genetic factors and environmental cues (Putterill et al. 2004; Verhage et al. 2014). In the present study, days to flowering increased over time in the case of two photosensitive varieties (BRRI dhan44 and BRRI dhan46) which indicates that their flowering is delayed due to low temperature. Generally, flowering should be promoted in short-day conditions but it was delayed because of low temperature. Thus, variation in days to flowering supported the idea that flowering of some photosensitive rice varieties delayed because of low temperature in the Aman season. It was also observed for two rice varieties, BRRI dhan46 and BRRI dhan31 where four transplanting dates were considered to study the effect of lowtemperature stress influenced by date of transplanting (Nahar et al. 2009). In future, these results need to be confirmed in separate studies. In between two moderate 

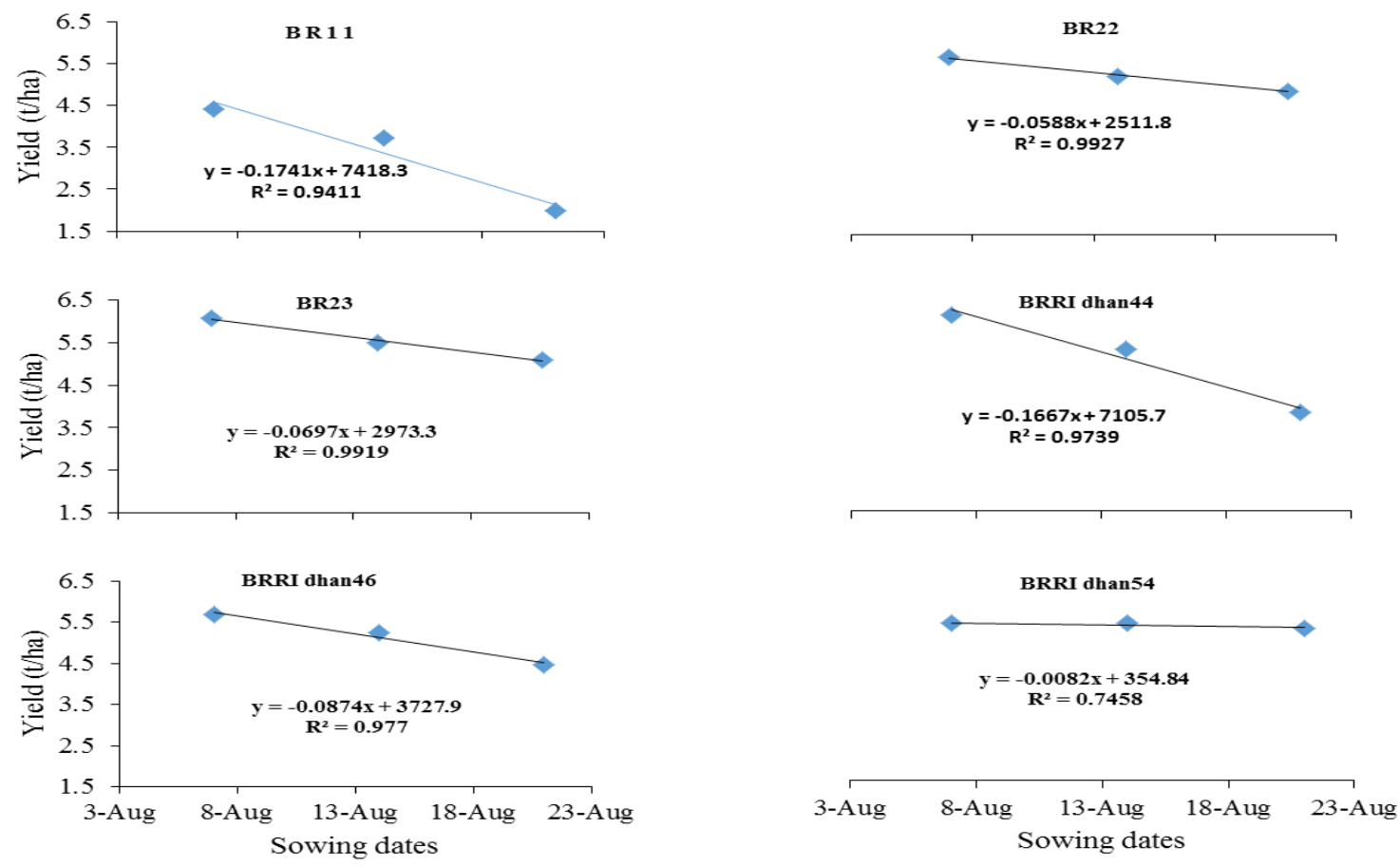

Fig. 2. Relationship between sowing dates and yield of six rice varieties in Aman season.

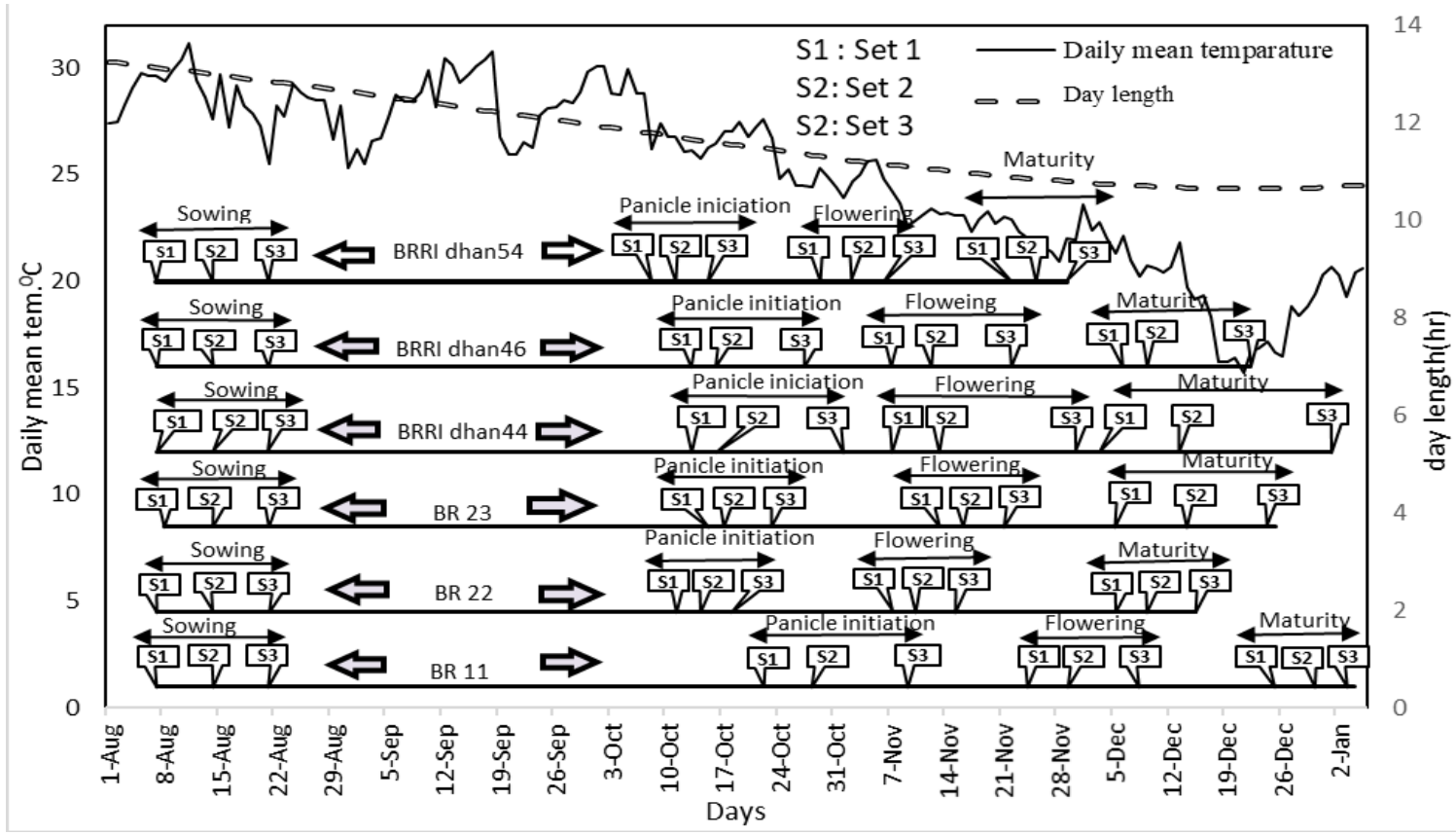

Fig. 3. Different growth stages (panicle initiation, flowering, and maturity) of each rice variety in relation to daily mean temperature $\left({ }^{\circ} \mathrm{C}\right)$ and day length $(\mathrm{hr})$ during the Aman season. 
photosensitive rice varieties, BRRI dhan 46 performed better while both the reproductive and ripening phases of BRRI dhan44 were extended due to low temperature, which is an undesirable trait in the delayed plantation. For days to maturity, both strong and moderate photosensitive rice varieties showed remarkable differences depending on planting time. Among strongly photosensitive rice varieties, BRRI dhan54 showed a gradual decrease in maturity time in case of BR22 and BR23 for a certain period. Similarly, the maturity of BRRI dhan 44 and BRRI dhan 46 was decreased only at the third set. These results indicate that BRRI dhan54 has higher benefits in delayed transplantation because of the decrease in growth duration over time. It has been reported that photosensitivity and thermosensitivity are especial traits in late planting and rice varieties showed a wide range of maturities in response to late planting. Besides, late maturing rice varieties exhibit a considerable reduction in growth duration compared with early and intermediate maturing varieties (Yabuta et al. 2010; Yasumoto et al. 2017).

Among the tested rice varieties, we also observed marked differences in grain yield depending on three sets of planting time. Grain yield of BRRI dhan54 did not differ significantly rather it showed consistency in case of delayed plantation. This result indicates that BRRI dhan54 has higher potentiality in a delayed plantation without any significant reduction in grain yield. In case of moderate photosensitive rice varieties, BRRI dhan46 showed superior performance in grain yield, which was further supported in comparison of days to panicle initiation and flowering. In previous studies, reduction in grain yield and days to maturity were found when the comparison was made among BR11, BR22, BR23 and Nizersail in relation to different planting dates (Ali et al. 1993). Moreover, the grain yield of the control variety BR11 was reduced drastically based on three sets of planting time, which indicates that weakly photosensitive rice has little or no benefit in delayed plantation. Furthermore, the relationship between sowing dates and grain yield supported that BRRI dhan54 has higher potentiality compared with other rice varieties.

\section{CONCLUSION}

Among the three sets of delayed planting, significant variation of evaluated agronomic traits indicated the presence of higher variability in performances of existing Aman rice varieties. Along with suitable agronomic performances, the strongly photosensitive rice varieties BR22, BR23, and BRRI dhan54 showed greater benefits in terms of grain yield when compared with moderately photosensitive rice varieties BRRI dhan44, and BRRI dhan46. Besides, the consistent grain yield of BRRI dhan54 suggested higher suitability of this rice variety in terms of vegetative growth and yield across delayed planting areas as well as in flood-affected areas of Bangladesh.

\section{REFERENCES}

Halder, K P, M A Rashid, S B Siddique, K U Ahmed, A A Choudhary. 1995. Influence of planting time on the growth and yield of some modern transplanted Aman rice. Bangladesh Rice J, 6: 711.

Shimono, H, M Okada, E Kanda, I Arakawa. 2007. Low temperature-induced sterility in rice: Evidence for the effects of temperature before panicle initiation. Field Crops Res, 101: 221-231.

Iftekharuddaula, KM, H Ahmed, S Ghosal, Z Moni, A Amin, M Ali. 2015. Development of new submergence tolerant rice variety for Bangladesh using marker-assisted back crossing. Rice Sci, 22: 16-26.

Shelley, I J, M Takahashi-Nosaka, M Kano-Nakata, M S Haque, Y Inukai. 2016. Rice cultivation in Bangladesh: present scenario, problems, and prospects. J Intl Cooper Agric Dev, 14: 20-29. 
Ali, M G, M A Mannan, K P Halder, S B Siddiquee. 1993. Effect of planting dates on the growth and yield of modern transplanted Aman rice. Ann Bangladesh Agric, 3(2):103-108.

Nahar, K, M Hasanuzzaman, R R Majumder. 2009. Effect of low temperature stress in transplanted Aman rice varieties mediated by different transplanting dates. A J Plant Sci, 2(3):132-138.

Parsons, B J, H J Newbury, M T Jackson. 1999. The genetic structure and conservation of Aus, Aman and Boro rices from Bangladesh. Genet Res Crop Evol, 46: 587-598.

Roy, B C, M A Hossain, M A I Khan.2003. Suitable transplanting time for the modern T. Aman rice varieties in tidal non saline wetland situation of Bangladesh. Pak J Bio Sci, 6 (7): 661-665.

STAR, Statistical Tool for Agricultural Research. 2013. http://bbi.irri.org/products

Yoshida, S. 1981. Fundamentals of rice crop science. International Rice Research Institute, Los Banos Laguna, Philippines, pp: 267.

Putterill, J, R Laurie, R Macknight. 2004. It's time to flower: the genetic control of flowering time. Bioessays, 26:363-373.
Verhage, L, G C Angenent, R G Immink. 2014. Research on floral timing by ambient temperature comes into blossom. Trends Plant Sci, 19: 583-591.

Izawa, T. 2007. Adaptation of flowering-time by natural and artificial selection in Arabidopsis and rice. J Exp Bot, 58: 3091-3097.

Song, Y H, J S Shim, H A Kinmonth-Schultz, T Imaizumi. 2015. Photoperiodic flowering: time measurement mechanisms in leaves. Annu Rev Plant Biol, 66: 441-464.

Islam, M R, M S Rahman, M H Rahman, M AAwal, M G Hossain. 1999. Effect of date of planting on rice yield and yield attributes of two advance mutants of rice in Aman season. Bangladesh J Nuclear Agric, 15: 34-40.

Yasumoto, S, N Maki, M Kojima, Y Ohshita. 2017. Changes in developmental duration of direct-seeded rice in a well-drained paddy field in response to late planting. Plant Production Sci, 20(3): 279-287.

Yabuta, S, S Hakoyama, S Inafuku, Y Fukuzawa, Y Kawamitsu. 2015. The photoperiodic sensitivity estimation at three growth phases of rice fractionated by turning point of leaf emergence and panicle initiation. Jpn J Crop Sci, 84: 64-68. 